\title{
Comportamiento de las relaciones migratorias entre Cuba y Estados Unidos desde 1959 hasta la actualidad
}

\author{
Behavior of the migratory relations between Cuba \\ and the USA from 1959 to the present
}

Elier Córdoba Carracedo*

ISSN IMPRESO 1870-7599 | ISSN RED CÓMPUTO 2448-7783 | 133-145

Ernesto Santiesteban Leyva**

RECIBIDO 11/12/18 | ACEPTADO 19/02/19

Enaidy Reynosa Navarro***

Resumen. El objetivo de este trabajo fue analizar cómo han evolucionado las relaciones migratorias Cuba-Estados Unidos desde 1959 hasta la actualidad. Para ello se explica cómo la Crisis de Octubre gestó un alto potencial migratorio en la isla, mientras que la Ley de Ajuste Cubano y el programa Éxodo incentivaron la emigración desordenada e ilegal. Se examinan también otros acontecimientos: la vinculación entre la cancelación del puente aéreo VaraderoMiami con los sucesos de la Embajada de Perú; las consecuencias del lanzamiento de la emisora Radio Martí para el cumplimiento del acuerdo migratorio de 1984; el derrumbe del campo socialista y el recrudecimiento del bloqueo económico contra Cuba activaron un nuevo potencial migratorio con características diferentes; la manera en que el «deshielo» - liderado por Raúl Castro y Barack Obama—, la eliminación de la política "Pies secos y pies mojados» y el programa Parole fueron esenciales para un avance bilateral; el modo en que la administración de Donald Trump obstaculizó el proceso de diálogo y restablecimiento bilateral retomado por Raúl Castro y Barack Obama.

Palabras clave: migración, relaciones bilaterales, acuerdos migratorios, diferendo CubaEstados Unidos.

\begin{abstract}
The objective of this work was to analyze how Cuba-USA migratory relations have been evolving from 1959 to the present day. For this, it is explained how the October Crisis generated a high migratory potential on the island. How the Cuban Adjustment Act and the Exodus program encouraged disorderly and illegal emigration? The link between the cancellation of the Varadero-Miami airlift with the events of the Peruvian Embassy. Likewise, the consequences of the launching of the Radio Martí station for the fulfillment of the migratory agreement of 1984. How the collapse of the socialist camp and the intensification of the economic blockade against Cuba served to activate a new migratory potential with different characteristics. Also, how the "thaw» — led by Raúl Castro and Barack Obama—, the elimination of the "Wet Feet and Dry Feet Policy» and the Parole program; they were essential for a bilateral advance. Finally, how the Donald Trump administration hampered the process of dialogue and bilateral reestablishment taken up by Raúl Castro and Barack Obama.
\end{abstract}

Keywords: migration, bilateral relations, immigration agreements, disagree USA-Cuba.

* Cubana. Universidad Oscar Lucero Moya, Holguín, Cuba. Correo-e: elier@cisat.cu

** Cubano. Universidad Oscar Lucero Moya, Holguín, Cuba. Correo-e: esantile@uho.edu.cu

**** Peruana. Universidad César Vallejo, Trujillo, Perú. Correo-e: ereynosa@ucv.edu.pe 


\section{Introducción}

El triunfo de la Revolución cubana determinó que Estados Unidos perdiera el liderazgo sobre un espacio regional donde ya contaba con un dominio económico, político, militar y cultural consolidado. Hasta ese entonces, «la hegemonía norteamericana se experimentaba como algo cultural: la cultura contribuyó a condicionar el orden moral, sobre el cual se basaba y se ejercía el poder, y por último en la forma en que el poder se regulaba y se resistía» (Pérez, 2015:6-7). Con ello se evidenció que el éxito de la hegemonía norteamericana en Cuba no fue sólo de control político y de dominación militar. La ruptura de esa hegemonía (cultural-política-militar), al triunfo de la Revolución, no fue aceptada por el gobierno de Washington; al contrario, se convirtió en motivación para un proceso de desentendimiento bilateral que después de más de cinco décadas continúa afectando a generaciones de cubanos dentro y fuera de la isla, a sus descendientes e incluso a ciudadanos norteamericanos quienes todavía no pueden viajar a la isla sin restricciones.

En la madrugada de 1 de enero de 1959, Fulgencio Batista (1901-1973) abandonó Cuba con una comitiva de cuatro aviones rumbo a Estados Unidos; en el camino reconsideró tal decisión y resolvió dirigirse a República Dominicana. Tan pronto las aeronaves tomaron vuelo, solicitó entrevistarse con el coronel Antonio Soto (piloto), según versión de éste:

Fulgencio Batista: i̇Soto, qué gasolina tenemos?

Antonio Soto: General, están llenos.

Fulgencio Batista: ¿̇Alcanza como para llegar a la República Dominicana?

Antonio Soto: Sí, cómo no, la distancia es más o menos igual.

Fulgencio Batista: No sé, creo que es mejor seguir a Santo Domingo. Los americanos me pueden hacer un número ocho (Pérez, 2015:6-7).

Los antecedentes de esta decisión tienen sus orígenes en una reunión llevada a cabo el 17 de diciembre de 1958 en Kuquine, la finca privada de Batista, cuando el embajador norteamericano en Cuba Earl Edward Tailer Smith (1903-1991) le planteó a Batista que abandonara el país. Éste no estuvo conforme con tal sugerencia, pero la aceptó pidiendo viajar a Daytona Beach. El embajador le recomendó que mejor fuera a España (Sánchez, 2013). 
Otro antecedente es que el gobierno de Daytona Beach había declarado a Batista en la década de 1950 como «hijo honorífico». Como se planteó, los tres aviones fueron para la Florida y en particular hacia Miami (Abreu, 1984); con lo que inició el proceso de los llamados exiliados cubanos, prófugos de la justicia por sus crímenes cometidos para el gobierno revolucionario; otros abandonaron el país ilegalmente en yates y otras embarcaciones.

Paralelamente, las primeras medidas radicales de la Revolución cubana coadyuvaron al incremento de la emigración, compuesta fundamentalmente por miembros de la burguesía cubana con vínculos en Estados Unidos, trabajadores de empresas norteamericanas con calificación profesional, además de 50 por ciento de los médicos, estomatólogos y profesores universitarios, y otras personas; todos influenciados por las campañas anticomunistas y por la dominación cultural y los supuestos valores de la sociedad receptora, que durante años había penetrado en Cuba y que tuvo su máxima expresión en los 1950.

\section{Desarrollo}

La primera oleada de inmigrantes desde Cuba hacia Estados Unidos tuvo lugar entre 1959 y 1962, estuvo conformada por personas de la burguesía media y alta, propietarios de fábricas, centrales, tiendas, almacenes, fincas, etcétera, que tenían vinculaciones políticas y empresariales. Al ser personas acaudaladas pudieron establecer negocios en Miami. Esta primera generación, como es opinión consensuada de los investigadores, estaba convencida de su regreso a Cuba en poco tiempo y que los norteamericanos eliminarían la Revolución y recuperarían de nuevo sus propiedades. Sin embargo, el fracaso de las agresiones como la invasión de Playa Girón (1961), la Operación Mangosta (1961) y la Crisis de Octubre (1962), fue indicio claro de que el regreso a Cuba estaba muy distante.

En la década de 1960 el gobierno de Washington concedió 500 millones de pesos a los exiliados para que desarrollaran pequeños negocios, cursos de inglés y otras actividades (Arbolella, 2015). En 1960 el presidente Dwight D. Eisenhower (1890-1969) creó el Centro de Refugiados Cubanos para dar ayuda a los exiliados, a pesar de que la ley norteamericana no reconoce el concepto de refugiado. Posterior a la Crisis de Octubre, ambos gobiernos decidieron suspender los vuelos aéreos comerciales. Hasta ese momento era posible viajar con visas de turistas, 
pero con esta decisión se fue acumulando un potencial migratorio que propició la emigración ilegal.

Posteriormente, y en ese contexto político, el gobierno cubano abrió el puerto de Camarioca en Matanzas. Ello permitió que desde Estados Unidos llegaran embarcaciones a Cuba para reclamar familiares. Por esa vía, entre octubre y noviembre de 1965, arribaron 2 mil 700 cubanos. En el periodo de 1962 a 1965 llegaron a Estados Unidos de forma ilegal 30 mil cubanos. En medio de esta compleja situación se acordó un memorando de entendimiento entre ambas naciones, que es el primer acuerdo migratorio que cuenta con 18 acápites (Miranda, 1989).

En noviembre de 1966, el presidente Lyndon B. Johnson (1908-1973) dictó la Ley de Refugiados Cubanos (Ley 89732) por la cual permitía adquirir la residencia permanente en Estados Unidos. Tal resolución hizo factible que 125 mil cubanos se convirtieran en residentes permanentes por haberse quedado durante más de dos años en ese país. Actualmente, esta ley se conoce como Ley de Ajuste Cubano. En ese periodo se estableció el puente aéreo Varadero-Miami (1965-1973), en el que llevaron a cabo los denominados «vuelos de la libertad», que transportaron a 2 mil 600 cubanos (90 por ciento de ellos con familiares en Estados Unidos). En 1973 el presidente Richard Nixon (1913-1994) suspendió los vuelos, lo que aumentó las salidas ilegales y creó tensiones entre ambas naciones a pesar de que el gobierno cubano siempre recurrió a la diplomacia. La eliminación de los vuelos creó una situación difícil para emigrar a Estados Unidos, lo que ocasionó hechos violentos en las embajadas de Venezuela y Perú que culminaron con la muerte de un custodio de esta última. El gobierno peruano se negó a entregar a los asesinos y Cuba retiró los custodios de la embajada andina, acto que provocó una crisis por la entrada de miles de personas. Muchos viajaron a Costa Rica y Perú donde fueron ubicados en condiciones de hacinamiento. Cabe destacar que en 1979 comenzó el diálogo entre la comunidad cubana en el exterior y el gobierno cubano, dicha iniciativa permitió que cubanos residentes en el extranjero pudieran visitar a sus familiares en la isla.

La compleja situación en la embajada peruana en Cuba dio lugar a una campaña anticubana promovida por gobiernos y medios de derecha de la región. En respuesta, el gobierno cubano abrió el puerto del Mariel, lo cual desencadenó una nueva oleada de emigrantes cubanos, pero con características económicas y culturales distintas a las anteriores. Este hecho, conocido como el «éxodo» del Mariel, hizo posible la llegada a Estados Unidos de 125 mil cubanos (Miranda, 1989) que no recibieron la condición de refugiados; al contrario, muchos fueron encarcelados, 
otros deambulaban por las calles, asaltando, robando, etcétera. Al mismo tiempo, algunos trataron de regresar a Cuba mediante el secuestro de aeronaves y lanchas. En 1981 el gobierno cubano cerró esta alternativa migratoria.

En diciembre de 1984 se firmó el acuerdo migratorio durante la administración de Ronald Reagan (1911-2004), quien se comprometió a recibir a 20 mil cubanos por año y devolver a 2 mil 746 que anhelaban regresar a la isla. Cinco meses después, Cuba suspendió el acuerdo como respuesta al lanzamiento de la emisora Radio Martí. Dicho acuerdo se reanudó el 21 noviembre de 1987, aunque nunca se cumplió con las 20 mil visas estipuladas. En ese periodo, la emigración cubana hacia Estados Unidos era legal e ilegal, directa y por terceros países.

En 1988 la Fundación Cubano Americana creó el programa Éxodo para permitir a los cubanos radicados en otros países llegar a Estados Unidos, incluso para algunos que todavía se hallaban en Perú. En tal sentido, Ernesto Rodríguez Chávez (1994) destaca que entre 1988 y 1993 se establecieron en el territorio norteamericano 65 mil cubanos emigrantes legales e ilegales. El promedio anual fue cinco veces menor que el promedio entre 1959 y 1962 y cuatro veces menor que en la etapa 1965-1973.

Como se aprecia, en el periodo 1988-1993 la emigración fue muy baja, pero a consecuencia de la crisis económica que desató la progresiva desaparición del campo socialista, se creó un nuevo potencial migratorio cuya explosión ocurrió después de los disturbios del 5 de agosto de 1994 en La Habana, conocidos como «el Maleconazo». El 12 de agosto Cuba eliminó las restricciones para abandonar el país de forma ilegal, con lo que inició la Crisis de los Balseros. Las personas se lanzaron al mar en todo tipo de embarcación, con el objetivo de ser rescatados por la guardia costera estadounidense; otros ingresaron a la base naval de Guantánamo. Por primera vez el gobierno norteamericano no aceptó a los ilegales. Más de 30 mil balseros cubanos llegaron a la base naval, unos fueron interceptados.

Esta realidad, compleja para ambas naciones, causó múltiples acusaciones a Cuba por parte de la prensa internacional. Sin embargo, ambos gobiernos entablaron conversaciones que llevaron a la firma del convenio del 9 de septiembre de 1994, según el cual Estados Unidos se comprometía a recibir un mínimo de 20 mil cubanos por año y Cuba no permitiría las salidas ilegales. El 2 de mayo de 1995 se hizo pública la ampliación de los acuerdos de 1994, en la que Estados Unidos se comprometía a aceptar a los cubanos que permanecían en la base naval de Guantánamo. Por primera vez en el acuerdo migratorio se incluyó a los ilegales. Los acuerdos sirvieron para normalizar las relaciones migratorias, 
aunque el potencial migratorio superaba a los $20 \mathrm{mil}$, por lo que demuestra que la opción de emigrar a Estados Unidos seguía latente.

El gobierno de George W. Bush de 2001 a 2009 llevó a cabo un conjunto de medidas para reforzar el bloqueo, incluyendo las relaciones migratorias en cuanto a la visita de cubanoamericanos a la isla, el envío de remesas, así como las conversaciones semestrales sobre relaciones migratorias (no es interés de este trabajo hacer un estudio de la política anticubana de dicho presidente). Por su parte, Barack Obama de 2009 a 2017, el 4 de febrero de 2009, eliminó las restricciones para viajar a Cuba, con la promulgación de la Ley de la Libertad (Cubahora, 2017), que suprimía las restricciones de su antecesor y otras medidas que limitaban el envío de remesas: «Se amplía de 500 a 2 mil dólares por trimestre, el límite en el envío de remesas a ciudadanos cubanos (...), se permite a instituciones financieras de Estados Unidos abrir cuentas en instituciones financieras de Cuba para facilitar las transacciones autorizadas entre ambos países» (Iusi, 2015:284). Del mismo modo, se acordó establecer diálogos sobre migración cada seis meses.

A partir de 1979 con los «marielitos» y los «balseros» de 1994 cambiaron las características socioeconómicas y culturales de la emigración cubana hacia Estados Unidos, que ahora tendrían una naturaleza económica, y se revelaba la segmentación de esta comunidad. Como se reconoce, hay una emigración económica y los llamados exiliados del principio de la Revolución han ido desapareciendo al pasar los años y otros han regresado al país de visita, lo que prueba que no eran perseguidos ni corrían el riesgo de perder su vida, también confirma el carácter económico de esa emigración.

La situación de tratamiento a los emigrados tuvo un momento de solución cuando en 2012 se aprobó la Nueva Ley Migratoria Cubana que derogó las leyes anteriores que contradecían las normas internacionales y a la vez concedían una condición de exiliados a los que abandonaban Cuba. Entre los aspectos principales de la vieja legislación migratoria destacaban los siguientes:

1. El decomiso de todos sus bienes de forma definitiva por la Ley 989.

2. A los jóvenes que debían cumplir con el servicio militar obligatorio se les prohibía o demoraba su autorización de salida del país.

3. Los ciudadanos que tenían un trabajo de cierta categoría eran despedidos y no podían realizar estudios universitarios.

4. Los emigrantes no podían regresar a su país de origen.

5. Tenían que realizar trabajos agrícolas, los hombres picaban cañas y las mujeres trillaban café. Tales tareas no eran tan voluntarias como se planteaban. 
Las medidas anteriores fueron producto de la confrontación ideológica y de la política agresiva norteamericana. El proceso de modificar y flexibilizar las relaciones migratorias venía ocurriendo desde 1984, cuando entró en vigor el Permiso de Residencia en el Exterior (PRE), por lo cual se ampliaba el permiso de salida indefinido, quienes lo obtenían podían visitar el país. En 1987 se puso en vigor el Permiso de Viajar al Exterior (PVE) para personas mayores de 55 años, pero se rebajó a 18 años en 1994, y podían permanecer fuera del país por un tiempo no mayor de 11 meses.

En 1994 se determinó que, por razones humanitarias, los emigrados de 60 años y los menores de 16 años desvalidos y sin amparo filial podían regresar al país. En 1996 se decidió que el emigrante podía regresar al país sin permiso de entrada, se instauró el Permiso de Salida Indefinido (PSI) para aquellas personas que contraían matrimonio con extranjeros, no se le aplicaba el decomiso de sus bienes y podían volver al país.

Todas esas medidas crearon un ambiente más fluido entre la emigración y la sociedad cubana, lo que ocasionó que 375 mil emigrados visitaran Cuba en 2010 y 400 mil en 2011, de ellos 300 mil procedían de Estados Unidos. Dichos incrementos se deben a la política de flexibilización ya analizada a la cual se unieron otras disposiciones, como la eliminación de la Carta de Invitación y el permiso de salida del país (requisitos previos al viaje solicitados por Cuba); asimismo, los emigrantes podían regresar cuando lo desearan dentro de un plazo de 24 meses a fin de mantener su nacionalidad, u optar por ser emigrados definitivos (Arboleya, 2015).

Al respecto, Wayne Smith (s/f, citado en Ferreira, 2015) sostiene: «Es evidente que las opiniones de la comunidad cubano-estadounidense deben tenerse en cuenta; pero ello de ninguna manera excluye una política más flexible y mejor adaptada al periodo posterior de la Guerra Fría». Esta expresión confirma la necesidad de un cambio de política que Barack Obama y Raúl Castro fueron capaces de representar cuando ambos exmandatarios acordaron restablecer las relaciones diplomáticas. Sin embargo, como alertó Ricardo Guadarrama (2015) en su estudio, el proceso de diálogo y recomposición entre cubanos y estadounidenses se ha visto bloqueado, toda vez que no hubo un tercer periodo demócrata que continuara con el proceso de normalización entre ambas naciones.

No obstante, el deshielo de 2015 influyó significativamente en las relaciones migratorias de ambas naciones, pues se facilitó la entrada de remesas al país y se establecieron 12 categorías para visitar la isla. Cabe aclarar que por la parte 
estadounidense, el ciudadano estadounidense todavía no tiene permiso de su gobierno para viajar como turista a Cuba. Con relación a dicho proceso, Carmelo Mesa-Lago (2015) destaca que antes del 17 de diciembre de 2014, 438 mil 179 turistas estadounidenses habían visitado la isla; de ellos, 258 mil 837 cubanoamericanos y 176 mil 334 norteamericanos. Los últimos aumentaron 45 por ciento con respecto al 2010; con lo que Estados Unidos se colocó como el segundo emisor después Canadá.

Se calcula que, sin la restricción mencionada, el turismo norteamericano en Cuba superaría los 2 millones de turistas al año. Aunque este cálculo, después de las medidas impuestas por Donald Trump a mediados de 2017, se ha vuelto poco probable. Otro aspecto de interés es que en enero de 2017 (últimos días del mandato de Obama) se firmó un nuevo acuerdo migratorio entre los dos gobiernos, mediante el cual se eliminaba la política «Pies secos y pies mojados» y el programa de Parole para profesionales cubanos, fundamentalmente de la salud, que emigran a Estados Unidos procedentes de terceros países. Por primera vez el acuerdo incluía a los emigrantes ilegales. Cuba se comprometió a aceptar a todos los emigrantes ilegales con posterioridad a la firma de los acuerdos sin someterlos a procesos judiciales, por lo que se aplicaban a los cubanos las mismas medidas que a los emigrados de otros países. En la declaración conjunta se plantea que

los Estados Unidos aplicarán sus leyes de emigración y asilo a los ciudadanos de otras partes de manera no selectiva, en otras palabras no discriminatorias y de conformidad con sus leyes y obligaciones internacionales. Los Estados Unidos de América seguirán garantizando la emigración desde la república de Cuba con un mínimo de 20 mil personas anuales (Cubadebate, 2017).

Este acuerdo constituye un avance importante para normalizar las relaciones migratorias, aunque se mantenía vigente la Ley de Ajuste Cubano. En ese contexto, habría que plantearse la siguiente interrogante: ìsi se elimina esta ley, disminuye la emigración a Estados Unidos? Las medidas migratorias anteriores han resultado un factor determinante para que Cuba tenga el tercer lugar en América Latina de residentes en Estados Unidos, superado únicamente por México y Puerto Rico. Carlos Alzugaray Treto apuntala estas cifras: «El área metropolitana de Miami tiene 5 millones de habitantes, pero cuenta con $850 \mathrm{mil} \mathrm{cu-}$ banos. Miami es, después de La Habana, la segunda ciudad de más cubanos del mundo, y está a 35 minutos de Cuba en avión» (2014:93). 
Dicho núcleo de cubanos no puede ignorarse y es claro que en su mayoría son emigrantes económicos y que el llamado exilio del inicio de la Revolución ha venido en decadencia creciente. Esta comunidad se ha ido formando en las distintas etapas estudiadas y se ha demostrado que no es homogénea, que se ha ido segmentando y que en su inmensa mayoría mantiene rasgos de la identidad cubana a pesar de la influencia de la sociedad receptora. Con relación a lo anterior, «todo el que nació en Cuba forma parte de la nación cubana, con distintos grados de nacionalidad e identidad, por supuesto esto es una decisión personal, puede haber gente que haya perdido determinados rasgos de la personalidad cubana» (Alzugaray, 2014:93).

Asimismo, cabe destacar que las últimas medidas tomadas por el Gobierno cubano contemplan el otorgamiento de la ciudadanía a los hijos de ciudadanos cubanos que hayan nacido en el exterior, así como a los hijos de los hijos de los ciudadanos cubanos nacidos en el exterior. En esa misma decisión se adoptaron nuevas medidas migratorias que no son objeto del presente trabajo. La mayoría de esa comunidad ha visitado el país y mantiene vínculos con su familia, lo cual obliga a reflexionar acerca de esas realidades.

En ese orden de ideas, Michael Bustamante expresa: «Hoy por hoy, la mayoría de los cubanos que llegan a Estados Unidos cada año se autodenominan simplemente emigrados, no inmigrantes, ni exiliados, ni cubanoamericanos» (2013:14). De esa forma privilegian una identificación con la tierra natal por encima de la tierra que los acoge. Esto define el cambio y las características nuevas asumidas por la emigración cubana en los últimos años.

El otro gran desafío que impone la emigración es el problema demográfico. En el texto de Jesús Arbolella Cervera se asume el criterio, consenso de otros investigadores, que la emigración será una constante en el futuro de la sociedad cubana (Alzugaray, 2014), pues constituirá, junto a los indicadores de fecundidad y mortalidad, uno de los factores más influyentes en el balance demográfico del país. Según indican tales estudios, para el 2030 la pérdida neta originada por la emigración será siempre superior a 40 mil personas por año, lo cual influirá en el monto poblacional y en el envejecimiento poblacional, en el que la emigración se suma al grupo de causales.

Los últimos giros o rumbos que han tomado los temas migratorios entre Cuba y Estados Unidos se han acoplado más al retroceso que al avance. En la investigación propuesta por Leandro Mongenfeld (2018) se explicó que Donald Trump, rodeado de anticastristas, empequeñeció todo avance vinculado con el 
proceso de deshielo iniciado por Barack Obama y Raúl Castro en 2014. La principal cuña fue la excusa de unos supuestos ataques sónicos contra el personal acreditado en la embajada estadounidense en La Habana. Bajo tal argumento, no corroborado por expertos hasta la fecha, el gobierno de Estados Unidos dio al traste con tensiones bilaterales que fueron desde el retiro de personal diplomático hasta el otorgamiento de visas a cubanos. De ese modo, Trump puso fin al deshielo a través de las medidas siguientes: restricción de viajes turísticos a los estadounidenses, reafirmación del bloqueo contra Cuba, reducción de viajes con fines no educativos y limitación de las negociaciones entre empresas estadounidenses y empresas estatales cubanas como el grupo GAESA. Según el análisis de Viktorovich y Abdul-Mazhitovich (2018), pese a que dichas resoluciones significaron nuevas trabas que no favorecían al pueblo cubano ni al estadounidense, no afectaron el deseo de los estadounidenses de visitar la isla. Muestra de ello es que el presidente de la Asociación de Operadores de Turismo de Estados Unidos, Terry Dale, replicó que Cuba estaba abierta a los negocios, que era una nación segura, bella y absolutamente legal para los viajeros estadounidenses que quisieran conocerla.

\section{Conclusiones}

La primera oleada migratoria de Cuba hacia Estados Unidos, posterior al triunfo de la Revolución y concentrada entre 1959-1962, estuvo compuesta fundamentalmente por cubanos acaudalados de clase media alta; condición económica que les permitió invertir en negocios múltiples. Dicho bloque migratorio albergaba la esperanza de regresar a Cuba una vez que hubiera fracasado la revolución naciente, hecho que no ocurrió. Por otro lado, en un primer momento el gobierno de Estados Unidos también apoyó económicamente a exiliados cubanos, con menos posibilidades económicas, para que pudieran invertir en pequeños negocios, se familiarizaran con el idioma y generaran espacios de vida autónomos.

Las tensiones bilaterales ocasionadas por la Crisis de Octubre en 1962, coadyuvaron a la concentración de un alto potencial migratorio en la isla. En esa etapa ambos gobiernos suspendieron los vuelos comerciales para quienes poseían visas de turistas. Tal decisión reorientó la emigración cubana por un rumbo ilegal. La Ley de Ajuste Cubano, además de haber sido incentivo para una emigración desordenada e ilegal que se encontraba en aumento en esa etapa, es considerada 
como una provocación y una medida unilateral antidemocrática que sólo aplica a la emigración cubana.

Adicionalmente, la orden de cancelar el puente aéreo Varadero-Miami (19651973) gestó los nefastos sucesos acaecidos en la embajada de Perú en La Habana, la cual fue apoyada con fuerza por los medios ultraderechistas de la región. Esos sucesos suscitaron otra situación migratoria conocida como el «éxodo» del Mariel (entre el 15 de abril y el 31 de octubre de 1980), cuyos nuevos migrantes tenían características socioculturales diferentes a los anteriores.

El lanzamiento de la emisora Radio Martí fue asumido por el gobierno cubano como una provocación, por ende, Cuba suspendió el acuerdo migratorio de 1984 mediante el cual Estados Unidos se comprometía a recibir 20 mil cubanos y a devolver 2 mil 746 que anhelaban regresar a la isla. Esta provocación confirma las intenciones del gobierno de Estados Unidos para, a través del exilio, desestabilizar el sistema social cubano.

El programa Éxodo de la Fundación Cubano Americana, al igual que la Ley de Ajuste Cubano, fomentaron la emigración ilegal, puesto que permitía a cubanos radicados en otros países llegar y establecerse en Estados Unidos, sin mayores complicaciones; los dos podrían considerarse disposiciones xenófobas porque aplicaban únicamente a cubanos, desestimando el carácter global de la inmigración, en específico en Estados Unidos, un país donde la emigración legal e ilegal tiene representación global.

Desde la década de 1980 hasta 1993 la emigración de Cuba a Estados Unidos es calificada de moderada a baja; sin embargo, el derrumbe del campo socialista y la emergencia económica que ello generó, más el recrudecimiento del bloqueo económico de Estados Unidos hacia Cuba, provocaron un desabastecimiento nacional que sirvió para que un sector de la sociedad cubana apostara de nueva cuenta por la emigración.

El restablecimiento de las relaciones diplomáticas de 2015 liderado por Raúl Castro y Barack Obama, independientemente de que Estados Unidos perseguía los mismos objetivos con Cuba y que el propio Obama en su discurso en La Habana motivara a los cubanos a hacer a un lado la historia, demostró que con voluntad política es posible avanzar en temas políticos y en otros de cooperación internacional como la ciencia, el cambio climático, la lucha antidrogas, la migración, el deporte, el arte, la alimentación, la medicina, el desarrollo de la pequeña y mediana empresa, etcétera. 
La eliminación de la política «Pies secos y pies mojados» y el programa Parole, aunque afectó directamente a la emigración ilegal, constituyó un paso bilateral sustantivo y positivo. Cuba aceptaba a todos los emigrantes ilegales deportados sin someterlos a procesos judiciales y Estados Unidos ponía fin a una política que motivaba la emigración ilegal y la fuga de talentos.

Con la llegada al poder de Donald Trump en enero de 2017, se obstaculizó el proceso de diálogo y recomposición que se venía gestando con fuerza a partir del deshielo de 2015; lo cual evidenció la poca prioridad que le otorgó a su política exterior con respecto a Cuba: «Su elemento más importante fue la continuación de una alianza en materia de seguridad y migración, que ya data de dos décadas, ampliada durante la Administración Obama» (Domínguez, 2017:16). No obstante, las consecuencias de su política de ruptura fueron contraproducentes en las aspiraciones de restablecimiento progresivo de las relaciones de todo tipo entre las dos naciones.

\section{Referencias}

Abreu, Ramiro (1984), En el último año de aquella república, La Habana, Ciencias Sociales. Alzugaray Treto, Carlos (2014), «Hacia una institucionalización creciente de los vínculos de Cuba con la emigración», Espacio Laical, 10(2), pp. 91-95, en http://www. espaciolaical.org/contens/38/9195.pdf

Arbolella Cervera, Jesús (2015), Cuba, los cubanos americanos y el fenómeno migratorio cubano, La Habana, Casa de las Américas.

Bustamante, Michael (2013), "Ley de Ajuste Cubano, subjetividades de la Diáspora y otros rompecabezas migratorios», Espacio Laical, 9(4), pp. 14-20, en http://docplayer. es/5041555-Ley-de-ajuste-cubano-subjetividades-de-la-diaspora-y-otrosrompecabezas-migratorios.html

Cubadebate (12 enero 2017), "Declaración conjunta Cuba-EE. UU. sobre temas migratorios», Cubadebate, en http://www.cubadebate.cu/noticias/2017/01/12/declaracionconjunta-cuba-eeuu-sobre-temas-migratorios/\#.W2pe4tjKjIU

Cubahora (26 de mayo de 2017), "Presentan «Ley de Libertad para Viajar a Cuba» en Senado de EE. UU.», Cubahora, en http://www.cubahora.cu/politica/presentan -ley-de-libertad-para-viajar-a-cuba-en-senado-de-eeuu

Domínguez, Jorge (2017), «Opciones para las relaciones entre Cuba y Estados Unidos durante la presidencia de Donald Trump», IdeAs (10), DOI: 10.4000/ideas.2139 
Ferreira, Rui (20 de julio de 2015), «Wayne Smith, el hombre que soñó con el deshielo entre Cuba y EE. UU.», El Mundo, en http://www.elmundo.es/internacional/201 5/07/20/55abbd0be2704ec03a8b4575.html

Guadarrama, Ricardo (2015), "Cuba y Estados Unidos: el largo proceso del reconocimiento. Latinoamérica", Revista de Estudios Latinoamericanos, 1(60), pp. 53-92, DOI: 10.1016/j.larev.2015.04.001

Iusi, Francesca (2015), «El inicio del proceso de normalización entre Estados Unidos y Cuba», Civitas Europa, 2(35), pp. 283-284, DOI: 10.3917/civit.035.0283

Mesa-Lago, Carmelo (2015), "Normalización de las relaciones entre EE. UU. y Cuba. Causas, prioridades, progreso, obstáculos, efectos y peligros», Real Instituto Elcano, pp. 1-43, en http://www.realinstitutoelcano.org/wps/wcm/connect/08319180484 ca6fea75eff2290640bff/DT6-2015-Mesa-Normalizacion-de-relaciones-entre-EEUUy-Cuba-causas-prioridades-progresos-obstaculos-efectos-y-peligros.pdf? MOD =A JPERES\&CACHEID =08319180484ca6fea75eff2290640bff

Miranda, Olivia (1998), Las relaciones migratorias Cuba-EE. UU., La Habana, Ciencias Sociales.

Mongenfeld, Leandro (2018), "La agresiva política de Trump hacia Cuba», Revista de la Red de Intercátedras de Historia de América Latina Contemporánea, 4(7), pp. 157-173, en https://dialnet.unirioja.es/servlet/articulo? codigo $=6230826$

Pérez, Louis (2015), Ser cubano. Identidad, nacionalidad y cultura, La Habana, Ciencias Sociales.

Rodríguez Chávez, Ernesto (1994), "Crisis migratoria EE. UU.-Cuba, 1994», Cuaderno Nuestra América, 22(II).

Sánchez Parodi, Ramón (2013), Cuba-EE. UU. Diez tiempos de una relación, La Habana, Ciencias Sociales.

Viktorovich, K.N. y Abdul-Mazhitovich, K.M. (2018), «Ку 6 а-сша : з и г з а г но рмализ ации отношений», Журналы РАН (7), pp. 5-19, DOI: 10.31857/ S0044748X0000020-1 